\title{
A clinical overview of bone marrow edema
}

\author{
M. Manara, M. Varenna
}

Division of Rheumatology, Gaetano Pini Institute, Milan, Italy

\section{SUMMARY}

Bone marrow edema (BME) is a descriptive term which identifies a specific magnetic resonance imaging (MRI) pattern that can be observed in a number of clinical entities, which are often characterized by pain as their main symptom, but show significant differences in terms of histopathological findings, causal mechanisms and prognosis. Bone marrow lesions in the subchondral bone of subjects with knee osteoarthritis (OA) seem to be associated with pain and progression of cartilage damage over time. Some histopathological studies of advanced OA have shown a prevalent fibrosis and bone marrow necrosis. BME of the subchondral bone in rheumatoid arthritis is associated with an infiltrate of inflammatory cells and osteoclasts and has a predictive value of further development of erosions. In spondyloarthritis, BME of the sacroiliac joints identifies an active sacroiliitis and is associated with histological inflammation and radiographic progression, whereas the relationship between BME lesions of the spine and syndesmophyte development is still controversial. BME syndromes (BMES), such as transient osteoporosis of the hip, regional migratory osteoporosis, and transient post-traumatic BMES, are characterized by a BME pattern on MRI and a self-limiting course. The potential evolution of BMES toward osteonecrosis is still controversial.

Key words: Bone marrow edema, Magnetic resonance imaging, Osteoarthritis.

\section{INTRODUCTION}

ince it was first described in 1988 (1), the interest in bone marrow edema (BME) has progressively increased over the last few years, as can be inferred by a growing amount of publications on this topic. This descriptive term has been applied to a number of clinical entities, which are all characterized by the same magnetic resonance imaging (MRI) pattern and often by pain as their main symptom, but show significant differences in terms of histopathologic pictures, causal mechanisms and prognosis.

From the radiological point of view, BME can be defined as an area of altered signal on the MRI of the bone, which shows an intermediate or low signal intensity on $\mathrm{T} 1$ weighted images and a high signal intensity on fat-suppressed, T2 weighted, and short tau inversion recovery sequences in comparison with the normal bone marrow (2). The presence of BME can be detected only by MRI and cannot be seen on plain
X-rays or computed tomography, even though in some clinical conditions associated with BME, such as transient osteoporosis of the hip (TOH), an area of localized osteoporosis can be visible on X-rays. The finding of BME on MRI is also frequently associated with an increased local uptake of the tracer on the bone scan.

The real meaning of BME from the histopathological point of view is still unclear. The altered signal pattern observed on MRI is probably related to a replacement of normal fatty bone marrow by a more water-rich material (3). Even if this alteration was assumed to be due to a real local edema, only a few studies actually confirm this hypothesis (4), whereas in the majority of histological samples there is no edema in the examined tissues but lymphocytic infiltrates, fibrosis, increased vascularization and less mineralized bone. For this reason in the most recent literature the term $B M E$ has been replaced in some cases by the more inclusive and generic definition of bone marrow lesions (BML), especially in 


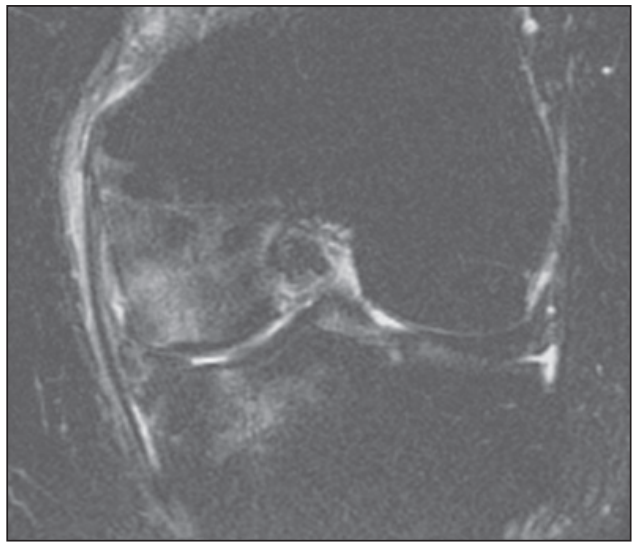

Figure 1 - Bone marrow lesions in knee osteoarthritis.

studies of subchondral lesions observed in osteoarthritis (OA) (Fig. 1), which are often well-defined and distinguishable from the more homogeneous and diffuse signal abnormalities visible in other BME related diseases, like the so-called BME syndromes (BMES) (5). The histopathological significance of BME could be different in distinct clinical entities, being probably more related to an inflammatory infiltrate in rheumatoid arthritis (RA), a real edema and a reduced bone mineralization in BMES, and fibrosis and bone marrow necrosis in advanced OA. However these different patterns could coexist in the same clinical entity. Moreover, it should be pointed up that interpretations derived from histological studies should be considered with caution due to unavoidable limitations related to collection techniques, which can make it difficult to detect the real presence of an edema on bone specimens mainly because of the time elapsed between BME appearance and histological examination.

If on one hand the clinical picture underlying BME may extremely vary, on the other the proposed pathogenic mechanisms are numerous and diverse, yet potentially concomitant. In a large proportion of cases, trauma has been called into question: acute trauma or chronic repeated stresses can induce a disruption of marrow trabeculae with leakage of interstitial fluid and hemorrhage to marrow spaces (6). Marrow edema can also be related to an increased marrow blood flow (hyperaemic) or an impaired vascular drainage (congestive) (6). Both conditions can cause an increased intraosseous pressure (4) which can lead to a diminished perfusion and hypoxia (7). Pain can arise from irritation of neurovascular structures induced by raised intra-medullary pressure or a direct insult to the neurovascular structure (6). A local acidosis due to an impaired circulation can act as a further mechanism inducing pain. Moreover, edema and pain could be mediated by the production of a number of local cytokines related to trauma and hypoxia. The local release of pro-inflammatory cytokines in the presence of an inflammatory infiltrate has been documented in inflammatory arthritis such as RA, where bone marrow fat is replaced by aggregates of lymphocytes and blood vessels (3). Not only could pain related to tumor-induced BME be caused by the direct impact of the mass on bone trabeculae, but also by the production of inflammatory mediators such as prostaglandins (6).

A further distinction among diseases characterized by BME concerns the clinical significance and consequently the prognosis of these entities. BMES are usually self-limiting and recover without sequelae in a variable time in the majority of cases. It is still debated whether avascular necrosis is an independent entity or a possible evolution of some cases of BMES (8). Conversely BML observed in OA patients have been related not only to pain (9), but also to cartilage damage progression and evolution toward joint derangement and the need for joint replacement (10). In RA, the sites of BME probably predict the later formation of bone erosions (11).

A classification of diseases associated with BME according to etiology has been proposed by Starr et al. (2) and more recently revised by Eriksen et al. (12) (Tab. I). This paper will focus on diseases associated with BME that are more frequently found in rheumatology practice and for which the finding of BME on MRI may play a role in influencing the therapeutic approach. A brief overview of the most common rheumatologic conditions in which BME could 
Table I - Etiologies of bone marrow edema.

\begin{tabular}{|l|}
\hline Trauma \\
Fracture (acute, osteoporotic, stress) \\
Local transient osteoporosis \\
Altered stress/biomechanics (plantar fasciitis, \\
tendinitis/enthesitis) \\
Bone bruise \\
Osteochondral injuries \\
\hline Degenerative lesions \\
Osteoarthritis \\
\hline Inflammatory lesions \\
Inflammatory arthropathies and enthesitis \\
Systemic chronic inflammation with fibrosis \\
\hline Vascular lesions \\
Avascular necrosis \\
CRPS-I \\
Sickle cell anemia \\
\hline Infectious lesions \\
Osteomyelitis \\
Diabetic foot \\
\hline Metabolic/endocrine lesions \\
Hydroxyapatite deposition disease \\
Gout \\
\hline latrogenic lesions \\
Local surgery \\
Radiotherapy \\
\hline Neoplastic lesions \\
\hline CRPS-l, Complex regional pain sindrome type \\
\hline
\end{tabular}

have a prognostic value or allow a better knowledge of the underlying pathogenic mechanisms will also be provided.

\section{OSTEOARTHRITIS}

For a long time OA has been considered as a disease mainly characterized by cartilage degeneration. In the last years this concept evolved and now OA is commonly considered as a pathological condition involving all the joint components, including the synovium and the subchondral bone. This tissue was disregarded for years due to its scarce accessibility, but the introduction of MRI in the clinical practice has shed a new light on the role of subchondral bone in OA pathogenesis and disease course. The finding of a possible association of BML detected on MRI with clinical manifestations such as pain and structural progression in terms of cartilage loss prompted researchers to investigate the clinical significance, the natural history and the pathological meaning of these lesions.
The association between BML and pain was suggested by a number of studies performed on patients affected by knee OA. In 2001 Felson et al. demonstrated a higher prevalence of BML in subjects with symptomatic knee OA than in patients without symptoms (9). This finding was confirmed in further cross-sectional studies, such as that by Sowers et al. which showed a significant association between $\mathrm{BML}>1 \mathrm{~cm}$ and symptomatic knee OA (13), and more recently by Driban et al. who found that large BMLs were associated with greater pain and their disappearance with pain resolution (14). Other studies yielded conflicting results: a cohort study by Kornaat et al. failed to demonstrate a significant association between BML and pain (15). A systematic review assessing the sources of pain in knee OA found an overall moderate evidence for an association between BML and pain, with 4 high-quality studies versus 1 demonstrating a positive association (16). The observed discrepancy in results could be related to the difficulty in assessing symptoms prospectively, since pain from knee OA is usually fluctuating despite the underling chronic condition (17). Moreover, other sources of pain, such as for example synovitis, could be concomitantly present and act as confounders. In this light, interesting results were provided by a recent study that demonstrated a higher frequency of knee pain fluctuations in patients with higher BML scores ( $\mathrm{p}$ for trend $=0.006)(18)$.

The natural history of BML is extremely variable, since a number of studies showed that BML can develop, fluctuate in size, and regress in OA patients, but also in the general population without OA (20). An association between BML and cartilage damage has been demonstrated in crosssectional and longitudinal studies (20-23). In 2003 Felson et al. observed an association between BML and ipsilateral radiographic progression in patients with knee OA (20). In a longitudinal study, Kothari et al. found that basal BMLs were predictive of cartilage loss in the same sub-region 2 years later (22). Furthermore BMLs were found to be predictive of joint replacement: 
in a longitudinal study on 109 subjects with knee OA, Tanamas et al. found that the risk of knee prosthesis over 4 years was significantly associated with higher BML scores (OR 1.57; 95\% CI: 1.04, 2.35) (10).

Although the clinical and prognostic meaning of BML in OA is quite well established, the underlying pathology and pathogenic mechanisms are still a matter of debate. The finding of a higher prevalence of BML in OA knee sub-regions where the load is higher, such as for example in the medial compartment in varus knees or the lateral compartment in valgus knees (20), strongly supports the hypothesis of a possible role of repeated trauma in the genesis of these lesions. Taljanovic et al. found a high number of micro fractures in bone biopsy specimens of patients with advanced hip OA and BME on MRI (24). Further studies did not confirm the finding of micro damages in BML of patients with knee OA. Conversely, specimens derived from BML of knee OA patients, when compared with adjacent bone without BML, showed a higher number of thicker trabeculae which were more plate-like (25-27). Interestingly, a reduced mineralization was observed with an increased osteoid volume (26). Many histological studies reported fibrosis and bone marrow necrosis, but little or no edema ( 28 , 29). It is noteworthy however that in almost all these studies bone specimens were derived from patients undergoing total joint replacement and, consequently, observed results may be related to advanced OA. It can be hypothesized that in earlier stages of the diseases findings could be different. In this regard a recent study differentiated BME edema patterns observed on MRI in edema-like lesions, with a complete homogenization after gadolinium intravenous injection, and necrosis-like lesions, which showed incomplete and inhomogeneous enhancement. Histopathology of edemalike lesions demonstrated a histological BME, with accumulation of eosinophilic extracellular fluid into trabecular spaces, while necrosis-like lesions were characterized by bone marrow fibrosis and, to a lesser degree, necrosis. Moreover, edema-like lesions were always found at the periphery of necrosis-like lesions: this arrangement suggests that edema-like lesions could represent a previous stage of necrosis-like lesions, which is potentially reversible (30). Perfusion abnormalities have been demonstrated in subchondral bone associated with BME. Aaron et al. observed that the rate of elimination of the contrast agent was lower in BML than in the unaffected bone, suggesting a venous obstruction blocking the outflow (7). More recently, Seah et al. found a significant correlation between BML size and the rate of contrast elimination in patients with knee $\mathrm{OA}$ in which perfusion parameters were investigated on dynamic contrast enhanced MRI (31). These results suggest that venous stasis could cause an intraosseous hypertension and consequently reduced perfusion and hypoxia. This mechanism could be responsible, at least in part, not only for pain, but also for osteocytes stimulation and consequently bone remodeling (7).

Even if the pathogenic mechanism of BML in OA still needs to be better clarified, as well as the mechanism linking subchondral bone to cartilage degradation, the observed association of bone alterations with symptoms and disease progression has aroused interest in the possibility of targeting bone in OA treatment. On this basis a number of studies suggested the use of bisphosphonates (BPS) and other anti-osteoporotic treatments in patients with $\mathrm{OA}$ and pain related to BML. A randomized-controlled trial demonstrated a higher reduction in knee pain and BML size in OA patients after treatment with Zoledronate than in the placebo group (32). A recent meta-analysis of efficacy of BPS in OA pointed out that there is still limited evidence for pain modulation by these molecules, but suggested that a better selection of the study population, i.e. patients with symptomatic OA and BML, should possibly offer more convincing results (33).

\section{RHEUMATOID ARTHRITIS}

If $\mathrm{OA}$ has long been considered a disease of cartilage, RA was regarded in the past 
as a pathological condition mainly involving the synovium. However, like in OA, the use of MRI shifted the focus on other joint components, such as subchondral bone.

The finding of a BME of the subchondral bone in patients affected by RA was first reported by Koenig et al. in 1986 (34). As the use of MRI progressively spread, the observation of BME become more frequent and a prevalence of BME in RA between $34 \%$ and $68 \%$ was described in subsequent studies (35). Interestingly, BME was detected more frequently at the wrist and in the second and third metacarpal (36) and, in early arthritis, at the metatarsal-phalangeal joints (37), which are sites where erosions are more likely to develop in RA patients. A number of cohort studies investigated the prognostic value of BME towards bone erosions. In a cohort of 42 patients with early RA, baseline BME was predictive of erosion at 1 year (38) and at 6 years [OR (95\% CI): $6.5(2.8,18.1)]$ (39). In another cohort of 84 patients with RA and disease duration of less than 1 year, BME was significantly associated with $\mathrm{X}$ rays and MRI erosive progression $(11,40)$. The predictive value of BME towards erosions has been confirmed in other studies, also regardless of the presence of synovitis $(41,42)$.

To better understand the pathological significance of BME in RA, a few studies analyzed the histopathology of subchondral bone in patients with BME detected on MRI (43). Jimenez-Boj et al. demonstrated an inflammatory infiltrate of lymphocytes, highly vascularized and sometimes adjoining cortical bone erosions (44). McQueen et al. confirmed the presence of a marrow infiltration and found that active osteitis was observed only in areas corresponding to BME on MRI, while osteitis was absent in samples without BME (45). A further study better detailed the nature of cells composing the inflammatory infiltrate, showing the presence of macrophages, plasma cells and T CD8+ and B lymphocytes (46). Subsequent studies using immunohistochemical techniques demonstrated that the marrow infiltrate was organized into follicles of B and T lymphocytes, often with a lymphoid-like morphological aspect (47). These results were confirmed in other studies (48). As for OA, the main limitation of histopathology studies is related to the source of bone samples, deriving from joints of patients undergoing prosthesis; therefore results reflect findings in patients with long-standing disease, while no direct evidence in early disease is available.

Even if an association between BME and erosions has been speculated based on clinical studies, the link between marrow infiltration associated to BME and bone resorption has not yet been defined on histopathology studies. Osteoclasts were identified in the subchondral bone of patients with RA in association with suchondral marrow inflammation (47). Dalbeth et al described a large number of osteoclasts in resorption lacunae adjacent to the osteitic region (46). However it is not yet clear if erosions could be related to the penetration of synovial inflammatory tissue in the subchondral bone or promoted by osteoclasts generated from mononuclear precursors in areas of osteitis (3). From a more general point of view, the relationship between osteitis and synovial inflammation in the pathogenesis of RA is still an intriguing issue. Different interpretations have been proposed: a primary role of synovial membrane was traditionally hypothesized, with synovial inflammation followed by bone involvement (the outside-in hypothesis), but more recently it has been suggested that osteitis could precede synovial inflammation (the inside-out hypothesis) (3). The second interpretation seems to be more applicable to other forms of arthritis than RA, such as for example spondyloarthritides. However, a partial autonomy of osteitis from synovitis cannot be excluded. What it is unquestionable is that, beyond its pathogenic significance, the BME of the subchondral bone in RA is a marker of disease activity and has a prognostic value. On this basis, BME detected on MRI is currently employed in clinical trials on patients with RA to assess early response to treatment and MRI scores including BME have been developed and validated to evaluate structural damage in RA (49). 


\section{SPONDYLOARTHRITIS}

The introduction of MRI in the clinical practice has deeply changed the approach to spondyloarthritis ( $\mathrm{SpA}$ ), because MRIdetected sacroiliitis has been introduced in the new Assessment of SpondyloArthritis Society (ASAS) classification criteria for axial $\mathrm{SpA}$ as a basic tool for diagnosis (50). Prior to this innovation, radiological sacroiliitis was diagnosed on the basis of x-rays, where changes can be detected only at advanced stages of the disease, whereas MRI already shows inflammation in its early stage, which often occurs years before structural damage develops (Fig. 2). Not only BME has been detected at sacroiliac joints in axial $\mathrm{SpA}$, but also at the spine, and it has been considered as a hallmark of inflammation (Fig. 3). Recent findings however suggested that BME at the sacroiliac joint could be a possible finding also in patients without clinical inflammatory back pain (51). Moreover, BME-like lesions of the spine were found to be related not only to inflammatory changes, but also to chronic structural changes (52). Therefore a considerable effort was spent by researchers to identify features associated with a clinical and prognostic significance and standardize the methodology to assess and define these lesions (53).

Among the inflammatory lesions that can be detected on MRI at the sacroiliac joints, only BME has been considered reliable in identifying active sacroiliitis (53). This finding is thought to reflect the presence of osteitis, and correlates with histological inflammation. Bollow et al. demonstrated an inflammatory infiltrate of T-cells, macrophages and scarce B-cells in biopsy samples of patients with MRI-detected sacroiliitis (54). Moreover they found a higher number of inflammatory cells in patients with active sacroiliitis on MRI than in patients with a reduced signal enhancement, and reduced signs of inflammation in patients with features of chronic sacroiliitis. Even if the prognostic role of BME of the sacroiliac joints for the later development of radiographic sacroiliitis is now well understood, recent studies suggest that not

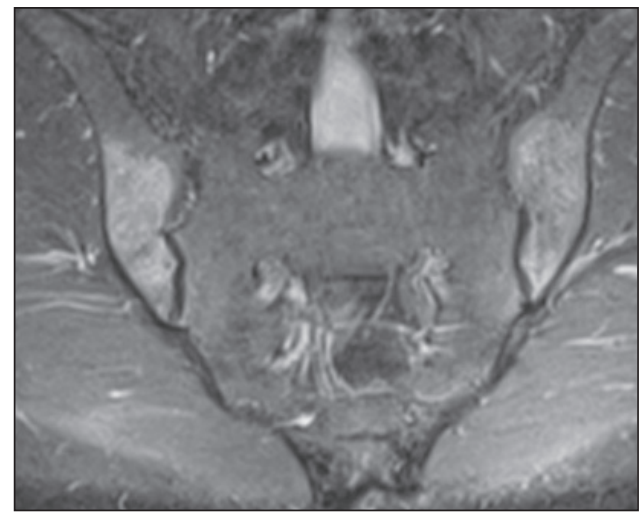

Figure 2 - Bone marrow edema of the sacroiliac joints with active sacroiliitis.

only the presence, but also the severity of this finding is relevant. In a prospective study on 40 patients with inflammatory back pain (IBP), the presence of severe sacroiliitis in association with HLA-B27 positivity was highly predictive of a diagnosis of ankylosing spondylitis (AS) at 8 years, with a positive likelihood ratio of 8.0. Conversely, patients with mild or no osteitis had a low likelihood to develop AS (55). In another study comparing patients with IBP to patients with mechanical back pain or healthy volunteers, BME of the sacroiliac joints was found also in the control group, although it was less frequent than in patients with IBP. The features of very early SpA could be differentiated from non-IBP based on BME severity (51). On this basis, the ASAS/Outcome Measures in Rheuma-

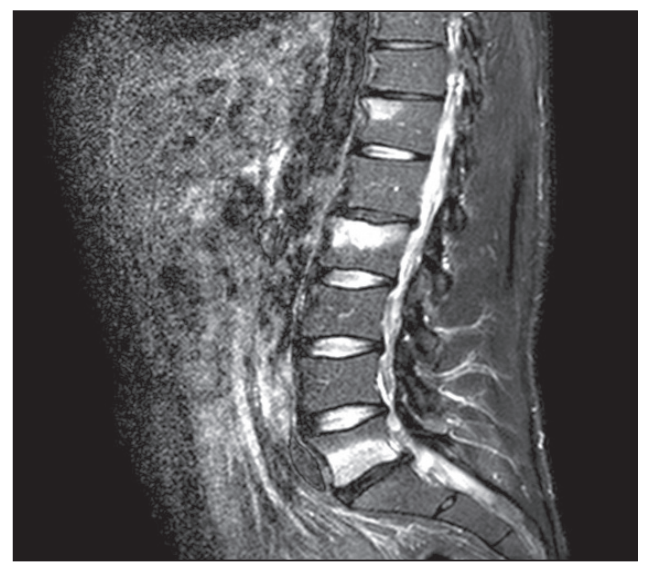

Figure 3 - Bone marrow edema of the spine in ankylosing spondylitis. 
tology Clinical Trials (OMERACT) MRI working group stated a minimum amount of signal required for the definition of sacroiliitis on MRI, which corresponds to at least $2 \mathrm{BME}$ lesions on a single slice or 1 lesion on at least 2 consecutive slices (53). The role of MRI-detected sacroiliitis as a marker of disease activity has recently been transposed also to clinical trials, since the extent of BME at the sacroiliac joints is considered as a good predictor of clinical response to treatment (56).

Studies evaluating the relationship between BME-like lesions in spine and later development of structural changes are very intriguing, since a number of pathogenic hypotheses can be inferred by their results. First of all, the appearance of an altered vertebral signal on MRI of the spine is extremely heterogenous. The main point is to differentiate between inflammatory lesions with a BME-like signal, in which MRI findings are related to bone marrow edema and hyperaemia during the inflammatory phase, and fatty lesions, which probably represent a later phase in which bone marrow tissue metaplasia to fat has occurred. Several prospective studies investigated the relationship between baseline MRI vertebral lesions and the development of syndesmophytes on X-rays, and all demonstrated that baseline inflammation was significantly associated with syndesmophytes development (57-59). However a large number of syndesmophytes developed from vertebral corners without signs of BME at baseline (59). Moreover, while a new syndesmophyte developed at follow up in a percentage of baseline corner inflammatory lesions (CILs) where inflammation had resolved, none of the CILs with persistent inflammation developed any syndesmophytes (58). These findings are intriguing, since they suggests an uncoupling between inflammation and structural damage, with new bone formation occurring where inflammation has resolved.

Another interesting observation supporting this hypothesis is the recent paradoxical finding that anti-TNF $\alpha$ therapy, while effectively suppressing inflammation in SpA patients, did not seem to prevent ra- diographic progression (60-62). On this basis a pathogenic hypothesis could be that an early inflammatory phase could be followed by an independent bone formation process, after inflammation has resolved. In this contest, TNF $\alpha$ could stimulate inflammation and at the same time slow down bone proliferation, by a down-regulation of Dickkopf-1 (Dkk1). Anti-TNF $\alpha$ treatment could therefore prevent bone formation only in a very early phase, before inflammatory cytokines can trigger the process leading to bone proliferation, but its efficacy at more advanced stages would depend on the ratio between the number of early inflammatory and advanced lesions (52). This hypothesis has been recently put into question by the observation that the treatment with TNF $\alpha$ inhibitors was associated with a reduced radiographic progression in a large cohort of patients with AS (63). Even if this finding may raise a controversy about the impact of TNF $\alpha$ inhibitors on spinal damage, this study confirmed that an early treatment was predictive of a better radiographic outcome.

Another pathogenic hypothesis puts forth a non-sequential model in which inflammation and bone formation act in parallel and are both triggered by a bio-mechanical factor represented by the entheseal stress (64). Enthesitis is one of the distinctive features of $\mathrm{SpA}$ and the enthesis has been hypothesized to be a primary disease site in SpA (65). MRI signs of active inflammatory enthesitis are found in association with soft tissue involvement and adjacent BME (66). Microanatomic and histopathologic studies have shown that the functional integration between the tendon and the bone at the entheseal site can lead to micro damage and bone remodeling and a local inflammation with hypervascularization (67). According to the entheseal stress hypothesis, a mechanical stress at the enthesis-bone interface could lead at the same time to new bone formation and production of pro-inflammatory cytokines; therefore bone formation could proceed completely or partially regardless inflammation.

The histological analysis of zygoapophyseal joints in AS patients undergoing spi- 
nal surgery and with MRI evidence of BME showed a correlation between BME on imaging and interstitial edema with mononuclear cell infiltrates on histology (68). The inflammatory infiltrate mainly included CD4+, CD8+ and CD20+ lymphocytes (69). These findings support the interpretations of BME lesions as being inflammatory and suggest that active spinal inflammation can be found also in patients with long-standing disease. Other immunohistochemical analyses found an increased expression of cathepsin $\mathrm{K}$ and MMP1 in AS patients with severe osteodestructive lesions, which imply an increased osteoclast activity which is responsible for the erosive damage (70). It could therefore be assumed that bone erosions in $\mathrm{SpA}$ have an osteoclast-mediated pathogenesis similar to RA, triggered by an underlying osteitis in which $\mathrm{T}$ cells predominate, unlike in RA. Conversely, bone formation could be mediated by other pathways like the Wnt pathway, as suggested by studies in which low levels of Wnt inhibitors, such as sclerostin and Dkk1, were found in AS patients compared to controls and were associated with increased radiographic progression $(71,72)$.

\section{BONE MARROW EDEMA SYNDROMES}

The definition of BMES refers to a number of clinical conditions characterized by a BME pattern with a self-limiting course. Most of them are found in the lower limbs, such as $\mathrm{TOH}$, regional migratory osteoporosis (RMO), and transient post-traumatic BMES.

$\mathrm{TOH}$ is the most frequent described condition among BMES (Fig. 4). It generally affects middle-aged men (30-50 years) or women in the third trimester of pregnancy (73). In most cases no triggering events can be found, but an abnormal mechanical stress (such as a long walk) has been described in some cases. The main symptom is represented by acute hip pain, exacerbated by loading, and is often associated with severe functional disability. In a few weeks

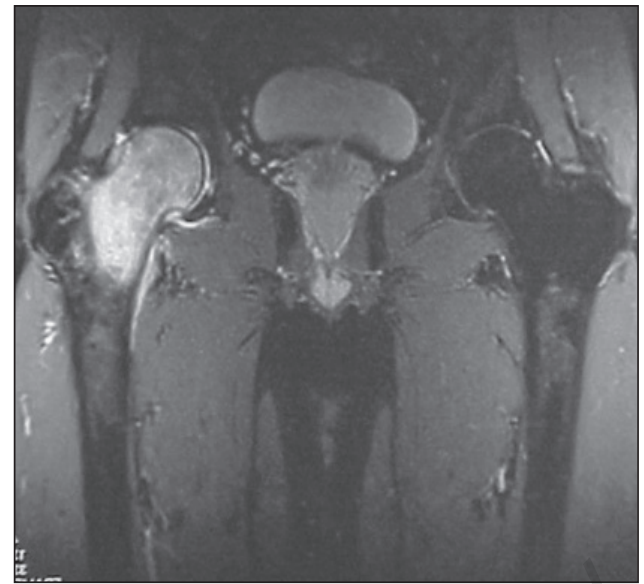

Figure 4 - Bone marrow edema of the femoral head and neck in transient osteoporosis of the hip.

from the onset of pain a diffuse osteoporosis of the femoral head can be observed on Xray. MRI shows a large homogenous BME involving the femoral head and sometimes extending into the femoral neck (5). A local increased uptake of the tracer can also be observed on bone scan. The clinical course of the disease is often self-limiting, with a spontaneous resolution in 4-24 months, but a possible evolution toward an osteonecrosis has been proposed, even if it is still an object of debate (8). Treatment with BPS seems to significantly shorten disease duration (74).

Even if pathogenic mechanisms underlying TOH have not yet been clearly identified, histological examination of bone biopsies harvested from patients with BME of the hip undergoing core decompression treatment revealed a diffuse interstitial edema of the marrow cavities associated with fibrous tissue deposition, angiogenesis and fat cell fragmentation (4). No increased osteoclastic activity was found, but trabeculae covered by osteoid with a reduced hydroxyapatite content, suggesting that radiological osteoporosis could be better related to bone mineral changes than to a true osteoclast mediated bone loss. A high intramedullary pressure was measured during the coring procedure.

A clinical course similar to $\mathrm{TOH}$ characterizes RMO and transient post-traumatic 
BMES, which both show a local homogeneous BME on MRI, a similar clinical condition characterized by pain, and a benign self-limiting clinical behavior. A previous trauma can always be identified in transient post-traumatic BMES, which frequently occurs in the knee, whereas BME and pain in RMO typically develop without a history of injury. The main distinctive feature of RMO from TOH is the polyarticular involvement that develops in the disease course, i.e. pain sequentially affects weight-bearing joints, and BME migrates in parallel. Only a retrospective or prospective evaluation of the patient can make it possible to distinguish an isolated $\mathrm{TOH}$ from an individual joint site in the context of RMO (73).

Even if a BME pattern on MRI can be found in some patients affected by a Complex regional pain syndrome type I (CRPSI), BME should not be considered a distinctive feature of CRPS-I (75). Nevertheless, it is a common mistake on the part of radiologists to refer to BME as an algodystrophy, even in absence of clinical hallmarks of this condition. CRPS-I is a complex regional painful condition which usually involves the extremities (hand or foot) and can be associated with sensory, autonomic, motor and trophic changes. Although an increased local uptake of the tracer on bone scan can be observed in a high percentage of cases in the early phases of the disease, recent diagnostic criteria only rely on clinical features (76). The clinical course of the disease usually goes through different clinical phases: an early warm stage, in which pain is associated with edema, functional limitation and often trophic and sensory symptoms, sometimes is followed by a dystrophic phase in which edema progressively reduces; then an atrophic phase can frequently be observed, when skin atrophy and contractures become prevalent. Unlike BMES, CRPS-I has a self-limiting course only in a minority of patients, while in most cases it evolves toward permanent disability. Clinical identification of patients affected by CRPS-I is therefore mandatory, since the clinical course can be modified by the treatment (77).
The recent demonstration of a good response to BPS treatment in patients affected by CRPS-I may allow a better clarification of possible mechanisms involved in the pathogenesis of the disease (71). Even if the characteristic increased uptake of the tracer on the bone scan could have suggested an osteoclast-mediated pathogenesis for the disease, studies on markers of osteoclastic activity and histopathological investigations failed to demonstrate an enhanced osteoclastic activity in CRPS-I (78). While increased blood flow and microvascular permeability could be responsible for the radiotracer uptake in the early phases, it is likely that the radiotracer accumulation in later phases depends on passive chemoadsorption of the BPS to hydroxyapatite (HAP) crystals related to an increased number of available binding sites on the bone surface due to the disappearance of lining cells. The local osteoporosis that can be observed on x-rays, rather than an osteoclast-mediated process, is more likely to be related to chemical dissolution of HAP crystals due to local hypoxia and acidosis, as can be inferred by histological studies in which a disappearance of HAP crystals and an elevated osteoid volume was demonstrated (4). In this pathogenic model, BPS could act with mechanisms that are not usually active when these molecules are employed to treat osteoporosis, due to the high local concentration achieved in CRPS-I. The efficacy of BPS in this clinical condition may rely on their ability to prevent HAP crystal dissolution in an acid milieu (79) and to decrease lactic acid production from various cell types (80), therefore reducing pain related to tissue acidosis and lowering neuropeptide release regulated by acid sensing receptors. Moreover BPS can inhibit the release of cytokines by inflammatory cells, which were found to be significantly increased in patients with CRPS-I (81-83). Another possible target of BPS might be the nerve growth factor, which can drive the release of substance $P$ and calcitonin gene-related peptide (84). Besides the possible mechanisms of action that can be hypothesized for BPS, overall these data suggests a central role of bone in 
CRPS-I, in which an impaired mineralization of bone rather than an altered turnover, and the local release of inflammatory cytokines and pain mediators, could account for the clinical manifestations of the disease.

\section{CONCLUSIONS}

$\mathrm{BME}$ is a frequent finding in several clinical conditions encountered in the daily rheumatology practice. Despite similar radiological appearance on MRI, this feature can underlie different pathological entities with their own pathogenic and prognostic significance. Clinical differentiation of diseases characterized by BME can influence therapeutic approach in consideration of the self-limiting or progressive nature of the condition. In recent years BME is increasingly considered as a marker of disease activity and as a possible target of therapy in chronic degenerative or inflammatory arthritis. Further studies are needed to better clarify the pathological and prognostic meaning of BME in several clinical conditions.

\section{REFERENCES}

1. Wilson AJ, Murphy WA, Hardy DC, Totty WG. Transient osteoporosis: transient bone marrow edema? Radiology. 1988; 167: 757-60.

2. Starr AM, Wessely MA, Albastaki U, PierreJerome C, Kettner NW. Bone marrow edema: pathophysiology, differential diagnosis, and imaging. Acta Radiolol. 2008; 49:771-86.

3. Schett G. Bone marrow edema. Ann N Y Acad Sci. 2009; 1154: 35-40.

4. Plenk H Jr, Hofmann S, Eschberger J, Gstettner M, Kramer J, Schneider W, et al. Histomorphology and bone morphometry of the bone marrow edema syndrome of the hip. Clin Orthop Relat Res. 1997; 334: 73-84.

5. Vande Berg BC, Lecouvet FE, Koutaissoff S, Simoni P, Malghem J. Bone marrow edema of the femoral head and transient osteoporosis of the hip. Eur J Radiol. 2008; 67: 68-77.

6. Eustace S, Keogh C, Blake M, Ward RJ, Oder PD, Dimasi M. MR imaging of bone oedema: mechanisms and interpretation. Clin Radiol. 2001; 56: 4-12.

7. Aaron RK, Dyke JP, Ciombor DM, Ballon D, Lee J, Jung E, et al. Perfusion abnormalities in subchondral bone associated with marrow edema, osteoarthritis, and avascular necrosis. Ann N Y Acad Sci. 2007; 1117: 124-37.

8. Hofmann S. The painful bone marrow edema syndrome of the hip joint. Wien Klin Wochenschr. 2005; 117: 111-20.

9. Felson DT, Chaisson CE, Hill CL, Totterman SM, Gale ME, Skinner KM, et al. The association of bone marrow lesions with pain in knee osteoarthritis. Ann Intern Med. 2001; 134: 541-9.

10. Tanamas SK, Wluka AE, Pelletier JP, Pelletier JM, Abram F, Berry PA, et al. Bone marrow lesions in people with knee osteoarthritis predict progression of disease and joint replacement: a longitudinal study. Rheumatology. 2010; 49: 2413-9.

11. Haavardsholm EA, Boyesen P, Ostergaard M, Schildvold A, Kvien TK. Magnetic resonance imaging findings in 84 patients with early rheumatoid arthritis: bone marrow oedema predicts erosive progression. Ann Rheum Dis. 2008; 67: 794-800.

12. Eriksen EF, Ringe JD. Bone marrow lesions: a universal bone response to injury? Rheumatol Int. 2012; 32: 575-84.

13. Sowers MF, Hayes C, Jamadar D, Capul D, Lachance L, Jannausch M, et al. Magnetic resonance-detected subchondral bone marrow and cartilage defect characteristics associated with pain and X-ray-defined knee osteoarthritis. Osteoarthritis Cartilage 2003; 11: 387-93.

14. Driban JB, Price LL, Lo GH, Pang J, Hunter DJ, Miller E, et al. Evaluation of bone marrow lesion volume as a knee osteoarthritis biomarker - longitudinal relationships with pain and structural changes: data from the osteoarthritis initiative. Arthritis Res Ther. 2013; 15:R112.

15. Kornaat PR, Kloppenburg M, Sharma R, Botha-Scheepers SA, Le Graverand MP, Coene $\mathrm{LN}$, et al. Bone marrow edema-like lesions change in volume in the majority of patients with osteoarthritis; associations with clinical features. Eur Radiol. 2007; 17: 3073-8.

16. Yusuf E, Kortekaas MC, Watt I, Huizinga TW, Kloppenburg M. Do knee abnormalities visualised on MRI explain knee pain in knee osteoarthritis? A systematic review. Ann Rheum Dis. 2011; 70: 60-7.

17. Gooberman-Hill R, Woolhead G, Mackichan F, Ayis S, Williams S, Dieppe P. Assessing chronic joint pain: lessons from a focus group study. Arthritis Rheum. 2007; 57: 666-71.

18. Zhang Y, Nevitt M, Niu J, Lewis C, Torner J, Guermazi A, et al. Fluctuation of knee pain and changes in bone marrow lesions, effusions, and synovitis on magnetic resonance imaging. Arthritis Rheum. 2011; 63: 691-9.

19. Dore D, Quinn S, Ding C, Winzenberg T, Zhai G, Cicuttini F, et al. Natural history and clinical significance of MRI-detected bone marrow lesions at the knee: a prospective study 
in community dwelling older adults. Arthritis Res Ther. 2010; 12: R223.

20. Felson DT, McLaughlin S, Goggins J, LaValley MP, Gale ME, Totterman S, et al. Bone marrow edema and its relation to progression of knee osteoarthritis. Ann Intern Med. 2003; 139: 330-6.

21. Raynauld JP, Martel-Pelletier J, Berthiaume MJ, Abram F, Choquette D, Haraoui B, et al. Correlation between bone lesion changes and cartilage volume loss in patients with osteoarthritis of the knee as assessed by quantitative magnetic resonance imaging over a 24-month period. Ann Rheum Dis. 2008; 67: 683-8.

22. Kothari A, Guermazi A, Chmiel JS, Dunlop D, Song J, Almagor O, et al. Within-subregion relationship between bone marrow lesions and subsequent cartilage loss in knee osteoarthritis. Arthritis Care Res. 2010; 62: 198-203.

23. Roemer FW, Guermazi A, Javaid MK, Lynch JA, Niu J, Zhang Y, et al. Change in MRIdetected subchondral bone marrow lesions is associated with cartilage loss: the MOST Study. A longitudinal multicentre study of knee osteoarthritis. Ann Rheum Dis. 2009; 68: 1461-5.

24. Taljanovic MS, Graham AR, Benjamin JB, Gmitro AF, Krupinski EA, Schwartz SA, et al. Bone marrow edema pattern in advanced hip osteoarthritis: quantitative assessment with magnetic resonance imaging and correlation with clinical examination, radiographic findings, and histopathology. Skeletal Radiol. 2008; 37: 423-31.

25. Hunter DJ, Gerstenfeld L, Bishop G, Davis AD, Mason ZD, Einhorn TA, et al. Bone marrow lesions from osteoarthritis knees are characterized by sclerotic bone that is less well mineralized. Arthritis Res Ther. 2009; 11: R11.

26. Kazakia GJ, Kuo D, Schooler J, Siddiqui S, Shanbhag S, Bernstein G, et al. Bone and cartilage demonstrate changes localized to bone marrow edema-like lesions within osteoarthritic knees. Osteoarthritis Cartilage. 2013; 21: 94-101.

27. Driban JB, Tassinari A, Lo GH, Price LL, Schneider E, Lynch JA, et al. Bone marrow lesions are associated with altered trabecular morphometry. Osteoarthritis Cartilage. 2012; 20: 1519-26.

28. Zanetti M, Bruder E, Romero J, Hodler J. Bone marrow edema pattern in osteoarthritic knees: correlation between MR imaging and histologic findings. Radiology. 2000; 215: 835-40.

29. Saadat E, Jobke B, Chu B, Lu Y, Cheng J, Li $\mathrm{X}$, et al. Diagnostic performance of in vivo 3-T MRI for articular cartilage abnormalities in human osteoarthritic knees using histology as standard of reference. Eur Radiol. 2008; 18 : 2292-302.
30. Leydet-Quilici H, Le Corroller T, Bouvier C, Giorgi R, Argenson JN, Champsaur P, et al. Advanced hip osteoarthritis: magnetic resonance imaging aspects and histopathology correlations. Osteoarthritis Cartilage. 2010; 18: 1429-35.

31. Seah S, Wheaton D, Li L, Dyke JP, Talmo C, Harvey WF, et al. The relationship of tibial bone perfusion to pain in knee osteoarthritis. Osteoarthritis Cartilage. 2012; 20: 1527-33.

32. Laslett LL, Dore DA, Quinn SJ, Boon P, Ryan E, Winzenberg TM, et al. Zoledronic acid reduces knee pain and bone marrow lesions over 1 year: a randomised controlled trial. Ann Rheum Dis. 2012; 71: 1322-8.

33. Davis AJ, Smith TO, Hing CB, Sofat N. Are bisphosphonates effective in the treatment of osteoarthritis pain? a meta-analysis and systematic review. PloS ONE. 2013; 8: e72714.

34. Koenig H, Lucas D, Meissner R. The wrist: a preliminary report on high-resolution MR imaging. Radiology. 1986; 160: 463-7.

35. McQueen FM. Bone marrow edema and osteitis in rheumatoid arthritis: the imaging perspective. Arthritis Res Ther. 2012; 14: 224.

36. Peterfy CG, Countryman P, Gabriele A, Shaw T, Anisfeld A, Tsuji W, et al. Magnetic resonance imaging in rheumatoid arthritis clinical trials: emerging patterns based on recent experience. J Rheumatol. 2011; 38: 2023-30.

37. Ostendorf B, Scherer A, Modder U, Schneider M. Diagnostic value of magnetic resonance imaging of the forefeet in early rheumatoid arthritis when findings on imaging of the metacarpophalangeal joints of the hands remain normal. Arthritis Rheum. 2004; 50: 2094-102.

38. McQueen FM, Stewart N, Crabbe J, Robinson E, Yeoman S, Tan PL, et al. Magnetic resonance imaging of the wrist in early rheumatoid arthritis reveals progression of erosions despite clinical improvement. Ann Rheum Dis. 1999; 58: 156-63.

39. McQueen FM, Benton N, Perry D, Crabbe J, Robinson E, Yeoman S, et al. Bone edema scored on magnetic resonance imaging scans of the dominant carpus at presentation predicts radiographic joint damage of the hands and feet six years later in patients with rheumatoid arthritis. Arthritis Rheum. 2003; 48: 1814-27.

40. Boyesen P, Haavardsholm EA, van der Heijde D, Ostergaard M, Hammer HB, Sesseng S, et al. Prediction of MRI erosive progression: a comparison of modern imaging modalities in early rheumatoid arthritis patients. Ann Rheum Dis. 2011; 70: 176-9.

41. Hetland ML, Ejbjerg B, Horslev-Petersen K, Jacobsen S, Vestergaard A, Jurik AG, et al. MRI bone oedema is the strongest predictor of subsequent radiographic progression in early rheumatoid arthritis. Results from a 2-year randomised controlled trial (CIMESTRA). Ann Rheum Dis. 2009; 68: 384-90. 
42. Hetland ML, Stengaard-Pedersen K, Junker P, Ostergaard M, Ejbjerg BJ, Jacobsen S, et al. Radiographic progression and remission rates in early rheumatoid arthritis - MRI bone oedema and anti-CCP predicted radiographic progression in the 5-year extension of the double-blind randomised CIMESTRA trial. Ann Rheum Dis. 2010; 69: 1789-95.

43. Bugatti S, Manzo A, Caporali R, Montecucco C. Inflammatory lesions in the bone marrow of rheumatoid arthritis patients: a morphological perspective. Arthritis Res Ther. 2012; 14: 229.

44. Jimenez-Boj E, Nobauer-Huhmann I, Hanslik-Schnabel B, Dorotka R, Wanivenhaus AH, Kainberger $\mathrm{F}$, et al. Bone erosions and bone marrow edema as defined by magnetic resonance imaging reflect true bone marrow inflammation in rheumatoid arthritis. Arthritis Rheum. 2007; 56: 1118-24.

45. McQueen FM, Gao A, Ostergaard M, King A, Shalley G, Robinson E, et al. High-grade MRI bone oedema is common within the surgical field in rheumatoid arthritis patients undergoing joint replacement and is associated with osteitis in subchondral bone. Ann Rheum Dis. 2007; 66: 1581-7.

46. Dalbeth N, Smith T, Gray S, Doyle A, Antill P, Lobo M, et al. Cellular characterisation of magnetic resonance imaging bone oedema in rheumatoid arthritis; implications for pathogenesis of erosive disease. Ann Rheum Dis. 2009; 68: 279-82.

47. Bugatti S, Caporali R, Manzo A, Vitolo B, Pitzalis $\mathrm{C}$, Montecucco $\mathrm{C}$. Involvement of subchondral bone marrow in rheumatoid arthritis: lymphoid neogenesis and in situ relationship to subchondral bone marrow osteoclast recruitment. Arthritis Rheum. 2005; 52: 3448-59.

48. Jimenez-Boj E, Redlich K, Turk B, HanslikSchnabel B, Wanivenhaus A, Chott A, et al. Interaction between synovial inflammatory tissue and bone marrow in rheumatoid arthritis. J Immunol. 2005; 175: 2579-88.

49. Ranganath VK, Strand V, Peterfy CG, Ostergaard M, Deodhar A, Landewe R, et al. The utility of magnetic resonance imaging for assessing structural damage in randomized controlled trials in rheumatoid arthritis: report from the imaging group of the American College of Rheumatology RA clinical trials task force. Arthritis Rheum. 2013. [Epub 2013/07/11.]

50. Rudwaleit M, van der Heijde D, Landewe R, Listing J, Akkoc N, Brandt J, et al. The development of Assessment of SpondyloArthritis international Society classification criteria for axial spondyloarthritis (part II): validation and final selection. Ann Rheum Dis. 2009; 68: 777-83.

51. Marzo-Ortega H, McGonagle D, O'Connor P, Hensor EM, Bennett AN, Green MJ, et al.
Baseline and 1-year magnetic resonance imaging of the sacroiliac joint and lumbar spine in very early inflammatory back pain. Relationship between symptoms, HLA-B27 and disease extent and persistence. Ann Rheum Dis. 2009; 68: 1721-7.

52. Maksymowych WP. MRI and X-ray in axial spondyloarthritis: the relationship between inflammatory and structural changes. Arthritis Res Ther. 2012; 14: 207.

53. Rudwaleit M, Jurik AG, Hermann KG, Landewe $\mathrm{R}$, van der Heijde $\mathrm{D}$, Baraliakos $\mathrm{X}$, et al. Defining active sacroiliitis on magnetic resonance imaging (MRI) for classification of axial spondyloarthritis: a consensual approach by the ASAS/OMERACT MRI group. Ann Rheum Dis. 2009; 68: 1520-7.

54. Bollow M, Fischer T, Reisshauer H, Backhaus M, Sieper J, Hamm B, et al. Quantitative analyses of sacroiliac biopsies in spondyloarthropathies: T cells and macrophages predominate in early and active sacroiliitis - cellularity correlates with the degree of enhancement detected by magnetic resonance imaging. Ann Rheum Dis. 2000; 59: 135-40.

55. Bennett AN, McGonagle D, O'Connor P, Hensor EM, Sivera F, Coates LC, et al. Severity of baseline magnetic resonance imaging-evident sacroiliitis and HLA-B27 status in early inflammatory back pain predict radiographically evident ankylosing spondylitis at eight years. Arthritis Rheum. 2008; 58: 3413-8.

56. Rudwaleit M, Schwarzlose S, Hilgert ES, Listing J, Braun J, Sieper J. MRI in predicting a major clinical response to anti-tumour necrosis factor treatment in ankylosing spondylitis. Ann Rheum Dis. 2008; 67: 1276-81.

57. Baraliakos X, Listing J, Rudwaleit M, Sieper J, Braun J. The relationship between inflammation and new bone formation in patients with ankylosing spondylitis. Arthritis Res Ther. 2008; 10: R104.

58. Maksymowych WP, Chiowchanwisawakit P, Clare T, Pedersen SJ, Ostergaard M, Lambert RG. Inflammatory lesions of the spine on magnetic resonance imaging predict the development of new syndesmophytes in ankylosing spondylitis: evidence of a relationship between inflammation and new bone formation. Arthritis Rheum. 2009; 60: 93-102.

59. van der Heijde D, Machado P, Braun J, Hermann KG, Baraliakos X, Hsu B, et al. MRI inflammation at the vertebral unit only marginally predicts new syndesmophyte formation: a multilevel analysis in patients with ankylosing spondylitis. Ann Rheum Dis. 2012; 71: 369-73.

60. van der Heijde D, Landewe R, Baraliakos X, Houben $\mathrm{H}$, van Tubergen A, Williamson P, et al. Radiographic findings following two years of infliximab therapy in patients with ankylosing spondylitis. Arthritis Rheum. 2008; 58: 3063-70. 
61. van der Heijde D, Landewe R, Einstein S, Ory P, Vosse D, Ni L, et al. Radiographic progression of ankylosing spondylitis after up to two years of treatment with etanercept. Arthritis Rheum. 2008; 58: 1324-31.

62. van der Heijde D, Salonen D, Weissman BN, Landewe R, Maksymowych WP, Kupper H, et al. Assessment of radiographic progression in the spines of patients with ankylosing spondylitis treated with adalimumab for up to 2 years. Arthritis Res Ther. 2009; 11: R127.

63. Haroon N, Inman RD, Learch TJ, Weisman $\mathrm{MH}$, Lee M, Rahbar MH, et al. The impact of tumor necrosis factor alpha inhibitors on radiographic progression in ankylosing spondylitis. Arthritis Rheum. 2013; 65: 2645-54.

64. Lories RJ, Luyten FP, de Vlam K. Progress in spondylarthritis. Mechanisms of new bone formation in spondyloarthritis. Arthritis Res Ther. 2009; 11: 221.

65. McGonagle D, Gibbon W, Emery P. Classification of inflammatory arthritis by enthesitis. Lancet. 1998; 352: 1137-40.

66. Eshed I, Bollow M, McGonagle DG, Tan AL, Althoff CE, Asbach P, et al. MRI of enthesitis of the appendicular skeleton in spondyloarthritis. Ann Rheum Dis. 2007; 66: 1553-9.

67. Benjamin M, Toumi H, Suzuki D, Redman S, Emery P, McGonagle D. Microdamage and altered vascularity at the enthesis-bone interface provides an anatomic explanation for bone involvement in the HLA-B27-associated spondylarthritides and allied disorders. Arthritis Rheum. 2007; 56: 224-33.

68. Appel H, Loddenkemper C, Grozdanovic Z, Ebhardt H, Dreimann M, Hempfing A, et al. Correlation of histopathological findings and magnetic resonance imaging in the spine of patients with ankylosing spondylitis. Arthritis Res Ther. 2006; 8: R143.

69. Appel H, Kuhne M, Spiekermann S, Ebhardt H, Grozdanovic Z, Kohler D, et al. Immunohistologic analysis of zygapophyseal joints in patients with ankylosing spondylitis. Arthritis Rheum. 2006; 54: 2845-51.

70. Neidhart M, Baraliakos X, Seemayer C, Zelder C, Gay RE, Michel BA, et al. Expression of cathepsin $\mathrm{K}$ and matrix metalloproteinase 1 indicate persistent osteodestructive activity in long-standing ankylosing spondylitis. Ann Rheum Dis. 2009; 68: 1334-9.

71. Appel H, Ruiz-Heiland G, Listing J, Zwerina J, Herrmann M, Mueller R, et al. Altered skeletal expression of sclerostin and its link to radiographic progression in ankylosing spondylitis. Arthritis Rheum. 2009; 60: 3257-62.

72. Heiland GR, Appel H, Poddubnyy D, Zwerina J, Hueber A, Haibel H, et al. High level of functional dickkopf-1 predicts protection from syndesmophyte formation in patients with ankylosing spondylitis. Ann Rheum Dis. 2012; 71: $572-4$

73. Korompilias AV, Karantanas AH, Lykissas MG, Beris AE. Bone marrow edema syndrome. Skeletal Radiol. 2009; 38: 425-36.

74. Varenna M, Zucchi F, Binelli L, Failoni S, Gallazzi M, Sinigaglia L. Intravenous pamidronate in the treatment of transient osteoporosis of the hip. Bone. 2002; 31: 96-101.

75. Crozier F, Champsaur P, Pham T, Bartoli JM, Kasbarian M, Chagnaud C, et al. Magnetic resonance imaging in reflex sympathetic dystrophy syndrome of the foot. Joint Bone Spine. 2003; 70: 503-8.

76. Harden RN, Bruehl S, Stanton-Hicks M, Wilson PR. Proposed new diagnostic criteria for complex regional pain syndrome. Pain Med. 2007; 8: 326-31.

77. Varenna M, Adami S, Rossini M, Gatti D, Idolazzi L, Zucchi F, et al. Treatment of complex regional pain syndrome type I with neridronate: a randomized, double-blind, placebo-controlled study. Rheumatology. 2013; 52: 534-42.

78. Varenna M, Zucchi F, Ghiringhelli D, Binelli L, Bevilacqua M, Bettica P, et al. Intravenous clodronate in the treatment of reflex sympathetic dystrophy syndrome. A randomized, double blind, placebo controlled study. Journal Rheumatol. 2000; 27: 1477-83.

79. Evans JR, Robertson WG, Morgan DB, Fleisch H. Effects of pyrophosphate and diphosphonates on the dissolution of hydroxyapatites using a flow system. Calcif Tissue Int. 1980; 31: 153-9.

80. Fast DK, Felix R, Dowse C, Neuman WF, Fleisch $\mathrm{H}$. The effects of diphosphonates on the growth and glycolysis of connective-tissue cells in culture. Biochem J. 1978; 172: 97-107.

81. Alexander GM, van Rijn MA, van Hilten JJ, Perreault MJ, Schwartzman RJ. Changes in cerebrospinal fluid levels of pro-inflammatory cytokines in CRPS. Pain. 2005; 116: 213-9.

82. Maihofner C, Handwerker HO, Neundorfer B, Birklein F. Mechanical hyperalgesia in complex regional pain syndrome: a role for TNFalpha? Neurology. 2005; 65: 311-3.

83. Uceyler N, Eberle T, Rolke R, Birklein F, Sommer C. Differential expression patterns of cytokines in complex regional pain syndrome. Pain. 2007; 132: 195-205.

84. Donnerer J, Schuligoi R, Stein C. Increased content and transport of substance $\mathrm{P}$ and calcitonin gene-related peptide in sensory nerves innervating inflamed tissue: evidence for a regulatory function of nerve growth factor in vivo. Neuroscience. 1992; 49: 693-8. 